\title{
INVENTARISASI DAERAH TERKENA DAMPAK BENCANA ANGIN PUTING BELIUNG DI WILAYAH PESISIR SELATAN KABUPATEN PURWOREJO
}

\author{
Oleh: \\ Rudiono \\ Program Studi Pendidikan Geografi STKIP PGRI Pontianak \\ email: onorudyasv@yahoo.co.id
}

\begin{abstract}
Abstrak
Pesisir selatan Purworejo merupakan daerah yang sering terlanda angin puting beliung. Pada tahun 2008 angin kencang terjadi hingga merobohkan sejumlah pohon dan menerbangkan atap rumah puluhan warga. Kapasitas masyarakat terhadap bencana angin puting beliung di lokasi penelitian perlu dinilai terlebih dahulu agar dapat menjadi bahan evaluasi kebijakan tentang penanganan bencana. Penelitian ini berupaya untuk melakukan pemetaan daerah terkena dampak dan inventarisasi daerah terkena dampak bencana angin puting beliung. Metode yang dipakai dalam penelitian ini adalah pemetaan partisipatif bersama anggota masyarakat yang dilanjutkan dengan pemetaan berjalan. Interpretasi citra satelit juga dilakukan untuk melihat kondisi wilayah sebelum melakukan pemetaan berjalan. Inventarisasi disusun dalam bentuk sistem informasi kebencanaaan menggunakan perangkat lunak desain web Adobe Dreamweaver CS4, bahasa pemrograman PHP, javascript program googlemap api v3, dan sistem manajemen basis data MySQL. Hasil penelitian ini menunjukkan bahwa sebaran daerah terlanda angin puting beliung tahun 2008 seluas $0,95 \mathrm{~km}^{2}$ tidak merata, dengan populasi objek terkena dampak terbanyak di Desa Ukirsari. Arah angin berasal dari barat daya ke timur laut. Panjang daerah yang dilintasi angin puting beliung tahun 2008 mencapai 4,30 km. Kekuatan angin mencapai skala Beaufort 9 . Hasil penelitian ini juga ditampilkan kedalam basis data sistem informasi berbentuk webGIS yang bernama Sistem Informasi Manajemen Dampak Puting Beliung.
\end{abstract}

Kata kunci: angin puting beliung, pemetaan partisipatif, kapasitas masyarakat

\section{THE INVENTORY OF CYCLONES AFFECTED AREA IN THE SOUTH COAST OF PURWOREJO}

\begin{abstract}
. Purworejo south coast is an area that is often devastated by a cyclone. In 2008, strong winds knocked down a number of trees, houses roofs and dozens of resident. The capacity of the societies dealing with cyclones at the research settings need to be assessed in advance to evaluate the policy on disaster management. This research aims to map and conduct an inventory to the areas affected by cyclones. The method used in this research is a participatory mapping by involving the society members. Then, it's continued by an on going mapping. The interpretation of satellite image was performed to see the condition of the area before conducting an on going mapping. The inventory was compiled in the form of disaster information systems by using web design software Adobe Dreamweaver CS4, PHP programming language, javascript googlemap fire v3, and the MYSQL database management system. The findings of this research show that the distribution of the areas devastated by a cyclone in 2008 covering an area of $0.95 \mathrm{~km} 2$ is uneven and the most affected population is in the village of Ukirsari. The direction of the wind is from the southwest to the northeast. The length of the area crossed by a cyclone
\end{abstract}


in 2008 reached $4.30 \mathrm{~km}$. The wind power reaches 9 Beaufort scale. The results of this research is also presented in the form of information system database WebGIS named Management Information Systems of Cyclones Impact.

Keywords : cyclones, participatory mapping, society capacity

\section{PENDAHULUAN}

Pesisir selatan Kabupaten Purworejo antara lain Kecamatan Grabag, Ngombol dan Purwodadi rawan dilanda angin kencang. Angin kencang terjadi hingga merobohkan sejumlah pohon dan menerbangkan atap rumah puluhan warga (Kedaulatan Rakyat, 24 Maret 2012). Pada tahun 2008 terjadi bencana angin puting beliung yang meluluh lantakkan permukiman warga. Kerugian material diperkirakan mencapai ratusan juta rupiah. Rumah dan bangunan yang roboh itu berada di tiga desa. Yakni Desa Ukirsari sebanyak 48 rumah, Desa Sumberagung 15 rumah, dan Desa Bakurejo 21 rumah. Total keseluruhan mencapai 84 rumah yang terkena dampak (Suara Merdeka, 12 Februari 2008). Pada tahun 2012, angin menerjang wilayah pesisir pantai selatan di wilayah Desa Nambangan, Kecamatan Grabag, hari Selasa 20 Maret 2012. Meski tidak ada korban jiwa maupun luka, tetapi angin telah mengakibatkan sejumlah pohon tumbang dan atap rumah warga beterbangan. Angin menerbangkan sejumlah atap rumah dari seng. Setidaknya ada belasan rumah yang atapnya rusak akibat kejadian ini (Suara Merdeka, 20 Maret 2012).

Tabel 1. Data Kejadian Angin Puting Beliung di Pesisir Selatan Purworejo

\begin{tabular}{|c|l|l|l|l|}
\hline No & \multicolumn{1}{|c|}{ Waktu } & \multicolumn{1}{|c|}{ Lokasi } & \multicolumn{1}{c|}{ Korban } & Jenis Bencana Angin \\
\hline 1 & 6 Maret 2007 & $\begin{array}{l}\text { Desa Pagak, Ngombol Desa } \\
\text { Malang, Ngombol }\end{array}$ & $\begin{array}{l}18 \text { rumah } \\
5 \text { rumah }\end{array}$ & $\begin{array}{l}\text { Angin Puting Beliung } \\
\text { Angin Puting Beliung }\end{array}$ \\
\hline 2 & 28 Desember 2007 & Desa Banyuyoso, Grabag & 2 rumah & Angin Topan \\
\hline 3 & 10 Februari 2008 & $\begin{array}{l}\text { Desa Ukirsari, Grabag Desa } \\
\text { Pasaranom, Grabag Desa } \\
\text { Bakurejo, Grabag } \\
\text { Desa Sumberagung, Grabag }\end{array}$ & $\begin{array}{l}4 \text { rumah } \\
21 \text { rumah } \\
16 \text { rumah }\end{array}$ & Angin Puting Beliung \\
\hline 4 & 27 Desember 2010 & Desa Jatikontal, Purwodadi & 8 rumah & Angin Puting Beliung \\
\hline 5 & 15 Januari 2011 & $\begin{array}{l}\text { Desa Sumberagung, Grabag } \\
\text { Desa Karangsari, Purwodadi } \\
\text { Desa Tunjungan, Ngombol } \\
\text { Desa Candi, Ngombol } \\
\text { rumah } \\
\text { Desa Aglik, Grabag }\end{array}$ & $\begin{array}{l}1 \text { rumah } \\
1 \text { rumah }\end{array}$ & Angin Puting Beliung \\
\hline 6 & 20 Maret 2012 & Desa Nambangan & $\begin{array}{l}\text { Belasan } \\
\text { rumah }\end{array}$ & Angin Puting Beliung \\
\hline
\end{tabular}

Sumber: Kantor Kesbangpolinmas Purworejo, 2012

Saat ini Badan Meteorologi Klimatologi dan Geofisika (BMKG) belum dapat memberikan prediksi potensi terjadinya angin puting beliung. Berbeda dengan dengan siklon tropis yang relatif mudah dideteksi dari satelit. Umur siklon tropis yang berkisar 10 hari dan luasnya regional mudah dikenali. Sedangkan puting beliung hanya 5-10 menit dan sangat lokal sehingga sulit dideteksi. Untuk itu perlu tetap kewaspadaan 
dalam menghadapi bencana ini terutama pada daerah-daerah yang kerap dilanda.

Daerah pertumbuhan siklon tropis paling subur di dunia adalah Samudra Hindia dan perairan barat Australia dan mencapai rerata 10 kali per tahun. Namun demikian, efek badai tersebut kadang sampai ke Indonesia. Ekor badai yang mencapai daerah perairan selatan Jawa seringkali menimbulkan angin kencang, hujan deras, dan tingginya gelombang laut. Daerah yang sering terkena pengaruh badai meliputi Kabupaten Boyolali, Klaten, Magelang, Purworejo, Kebumen, Cilacap hingga Banyumas dimana oleh masyarakat setempat dinamakan angin puting beliung (GLG Jawa Tengah, 2008).

Adapun tujuan penelitian ini adalah sebagai berikut: (1) memetakan wilayah secara spasial daerah yang pernah terlanda bencana angin puting beliung tahun 2008, (2) menganalisis bagaimana karakteristik kejadian puting beliung di daerah penelitian yang meliputi jumlah kerusakan dan pola sebaran daerah terlanda, dan (3) inventarisasi daerah terkena dampak angin puting beliung dalam bentuk website GIS sebagai media untuk evaluasi pemangku kebijakan terhadap penanganan pascabencana dan respon dari stakeholder lokal terkait sistem informasi ini.

\section{METODE}

Sebaran daerah terlanda diperoleh dari kegiatan pemetaan partisipatif bersama masyarakat desa dan aparatur pemerintah desa di lokasi terpilih.Variasi tingkat bahaya diperoleh dari hasil tumpangsusun antara Citra Satelit Quickbird 2010, peta RBI, peta Penggunaan Lahan dengan Peta Kepadatan Penduduk. Variasi tingkat bahaya disajikan secara kualitatif (rendah, sedang dan tinggi). Inventarisasi daerah terkena dampak bencana dilakukan dengan penyusunan database dalam bentuk sistem informasi kebencanaan menggunakan perangkat lunak desain web Adobe Dreamweaver CS4, bahasa pemrograman PHP, javascript program googlemap api v3, dan sistem manajemen basis data MySQL.

\section{HASIL DAN PEMBAHASAN}

Lokasi penelitian ini berada dalam wilayah administrasi Kecamatan Grabag Kabupaten Purworejo yang merupakan salah satu kecamatan di pesisir selatan Pulau Jawa yang langsung berbatasan dengan Samudera Hindia. Luas daerah penelitian ini adalah Adapun batas-batas administrasi daerah penelitian sebagai berikut:

Sebelah timur : Desa Munggangsari dan Desa Dudukulon

Sebelah barat : Desa Tlogo Kecamatan Mirit Kabupaten Kebumen

Sebelah utara : Desa Rowodadi, Desa Bendungan dan Desa Nambangan

Sebelah selatan : Desa Kertojayan

\section{Sebaran Daerah Terlanda}

Dengan melakukan pemetaan partisipatif yang melibatkan penduduk, penelitian ini mendapatkan sebaran daerah terlanda berdasarkan persepsi penduduk. Pemetaan partisipatif ini diawali dengan kegiatan delineasi atau membatasi daerahdaerah yang pernah terkena dampak langsung menggunakan peta yang telah disiapkan oleh peneliti. Kegiatan pemetaan partisipatif ini dilakukan bersamaan dengan pembagian kuesioner yang diisi oleh penduduk. Setelah penduduk yang 
dipilih sebagai responden mengisi kuesioner, kemudian melakukan identifikasi atas posisi rumah yang pernah terkena dampak langsung.

Selanjutnya dilakukan kroscek di lapangan guna melihat kesesuaian antara gambaran yang di peta dengan aslinya. Dalam kegiatan kroscek ini, titik-titik yang pernah terlanda di plotting menggunakan GPS agar dapat diolah lebih lanjut menjadi peta sebaran daerah terkena dampak langsung. Cek lapangan ini dimaksudkan agar daerah terkena dampak langsung ini dapat diketahui posisi tepatnya.

Dalam pengukuran secara spasial dengan menggunakan perangkat lunak ArcGIS 9.3, luas daerah yang pernah terkena dampak ini seluas $0,95 \mathrm{~km}^{2}$ Sedangkan panjangnya lintasan angin puting beliung yang melanda sepanjang 4,30 km kearah timur laut. Pada tampilan peta citra 3.2 dapat pula diamati bahwa terjadi pelemahan kecepatan angin yang berasal dari arah barat daya menuju timur laut. Pengamatan ini didasarkan oleh perbedaan kerapatan objek yang terkena dampak langsung. Berdasarkan gambar, angin lebih kencang melanda wilayah Desa Ukirsari daripada desa lainnya. Adapun gambar yang dimaksud seperti berikut ini.
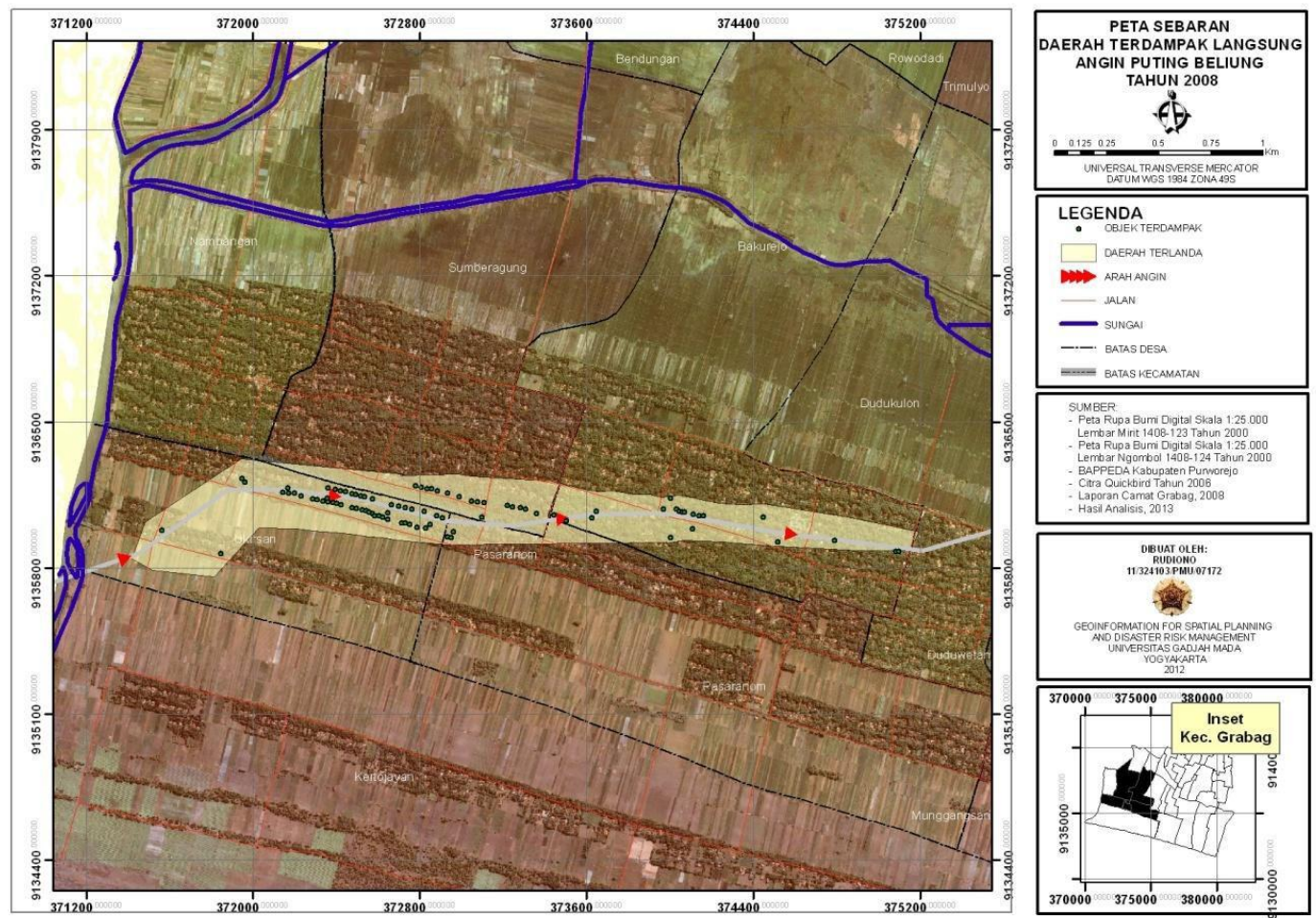

Gambar 1. Peta Sebaran Daerah Terkena dampak Langsung Tahun 2008

\section{Penentuan Kelas Bahaya Angin}

Berdasarkan definisi dari United Nations-International Strategy for Disaster Reduction (UN-ISDR), bahaya (hazard) adalah sebuah fenomena yang berbahaya, atau kondisi yang dapat menyebabkan hilangnya nyawa, cedera atau dampak kesehatan lain, kerusakan harta benda, hilangnya mata pencaharian dan layanan, gangguan sosial dan ekonomi, atau kerusakan lingkungan (http://www.unisdr.org diakses tanggal 5 April 2013). Bahaya ini dibedakan menjadi lima kelompok: 
1. Bahaya beraspek geologi, antara lain gempabumi, tsunami, gunungapi. longsor.

2. Bahaya beraspek hidrometerologi, antara lain: banjir, kekeringan, angin topan, gelombang pasang.

3. Bahaya beraspek biolog, antara lain : wabah penyakit, hama dan penyakit tanaman.

4. Bahaya beraspek teknologi, antara lain : kecelakaan transportasi, kecelakaan industri, kegagalan teknologi.

5. Bahaya beraspek lingkungan, antara lain : kebakaran hutan, kerusakan lingkungan, pencemaran limbah.

Dalam kaitan ini, bahaya angin puting beliung termasuk pada suatu suatu bahaya yang beraspek hidrometeorologi. Secara spesifik UN-ISDR kemudian memberikan definisi bahaya hidrometeorologi yaitu proses atau fenomena atmosfer, hidrologi atau oseanografi alam yang dapat menyebabkan hilangnya nyawa, cedera atau dampak kesehatan lain, kerusakan harta benda, hilangnya mata pencaharian dan layanan, gangguan sosial dan ekonomi, atau kerusakan lingkungan.

Untuk melakukan penilaian terhadap kelas bahaya, kemudian perlu dilakukan identifikasi terhadap jumlah objek terkena dampak (OTD) dan luasan sebaran daerah terkena dampak (DTD) berdasarkan penggunaan lahannya seperti ditampilkan pada Tabel 2.

Tabel 2. Tabel Sebaran Objek dan Daerah Terkena Dampak

\begin{tabular}{|c|c|c|}
\hline \multicolumn{1}{|c|}{ Input } & Kategori & $\begin{array}{c}\text { Jumlah (unit)/ } \\
\text { Luas }\left(\mathbf{k m}^{\mathbf{2}} \mathbf{)}\right.\end{array}$ \\
\hline \multirow{4}{*}{ 1. Jumlah objek terkena dampak } & Rumah penduduk & 87 unit \\
\cline { 2 - 3 } & Fasilitas ibadah & 1 unit \\
\hline \multirow{4}{*}{$\begin{array}{l}\text { 2. Penggunaan lahan di daerah } \\
\text { terkena dampak }\end{array}$} & Air tawar & $0 \mathrm{~km} 2$ \\
\cline { 2 - 3 } & Rawa & $0 \mathrm{~km} 2$ \\
\cline { 2 - 3 } & Belukar/semak & $0 \mathrm{~km} 2$ \\
\cline { 2 - 3 } & Sawah irigasi & $0 \mathrm{~km} 2$ \\
\cline { 2 - 3 } & Kebun & $0 \mathrm{~km} 2$ \\
\cline { 2 - 3 } & Permukiman & $0,793 \mathrm{~km} 2$ \\
\cline { 2 - 3 } & Ladang/tegalan & $0,197 \mathrm{~km} 2$ \\
\hline
\end{tabular}

Sumber: analisis data penelitian, 2013

Asumsi dasar dalam penentuan kelas bahaya dipengaruhi oleh faktor berikut:

a. Semakin banyak jumlah objek yang terkena dampak di suatu wilayah akan semakin tinggi kelas bahaya.

b. Penggunaan lahan pada daerah yang terkena dampak lebih banyak terdapat pada lahan permukiman sehingga penentuan kelas kelas lebih mengacu pada permukiman terkena dampak dengan memperhitungkan jumlah kerugian yang diderita korban.

Cara perhitungan kelas bahaya ini berdasarkan klasifikasi dengan menggunakan rumus:

Interval $=\frac{\text { Jumah OTD Tertinggi }- \text { Jumah OTD Terendah }}{\text { Jumlah Kelas Bahaya }}$ 
Jumlah kelas bahaya dalam penelitian ini telah ditentukan sebanyak tiga kelas yaitu bahaya tinggi, bahaya sedang, dan bahaya rendah. Hasil perhitungan ini kemudian diperoleh:

lnterval $=\frac{45-0}{3}=15$

Sehingga kelas bahaya yang diperoleh berdasarkan interval nilai tersebut seperti dalam Tabel 3.

Tabel 3. Penentuan Kriteria Kelas Bahaya

\begin{tabular}{|l|c|c|}
\hline No & $\begin{array}{c}\text { Jumlah Objek Terkena Dampak } \\
\text { (dalam setiap polygon daerah } \\
\text { terkena dampak) }\end{array}$ & Kriteria Kelas Bahaya \\
\hline 1 & $31-45$ & Tinggi \\
\hline 2 & $16-30$ & Sedang \\
\hline 3 & $0-15$ & Rendah \\
\hline
\end{tabular}

Kriteria kelas bahaya ini digunakan untuk menilai jumlah objek terkena dampak yang sifatnya kuantitatif menjadi nilai yang bersifat kualitatif. Selanjutnya dalam penentuan kelas bahaya ini dilakukan olah data spasial dengan menggunakan software ArcGIS 9.3 dengan cara interseksi antara layer objek terkena dampak, layer sebaran daerah terlanda dan layer penggunaan lahan. Hasil dari metode ini dituangkan dalam bentuk peta kelas bahaya seperti Gambar 2.

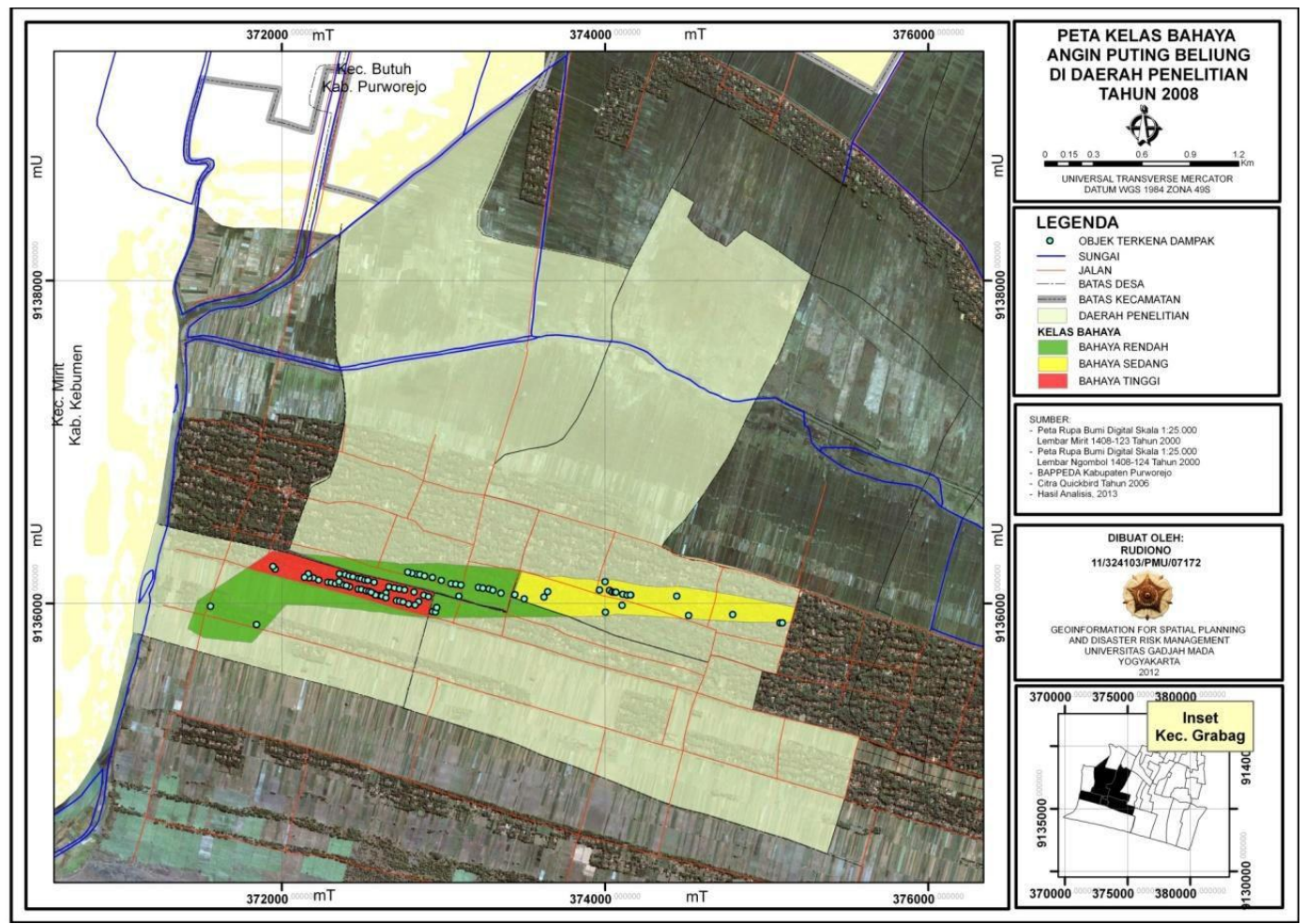

Gambar 2. Peta Kelas Bahaya Angin Puting Beliung Tahun 2008 
Pada Gambar Peta 2, wilayah-wilayah yang memiliki kelas bahaya rendah ditunjukkan dengan warna hijau. Kelas bahaya rendah pada peta ini meliputi sebagian permukiman dengan jumlah OTD terendah dan sebagian tegalan di Desa Ukirsari. Sementara itu, permukiman dengan jumlah OTD sedikit di Desa Sumberagung dan Desa pasaranom juga memiliki kelas bahaya rendah. Di Desa Bakurejo memiliki daerah dengan kelas bahaya sedang pada daerah permukiman seperti ditunjukkan dengan warna kuning. Jumlah OTD terbanyak berdasarkan penggunaan lahan permukiman terletak di Desa Ukirsari, sehingga pada daerah yang pernah terkena dampak ini memiliki kelas bahaya tinggi seperti ditunjukkan dengan warna merah. Artinya, daerah dengan jumlah objek terkena dampak (OTD) tinggi, maka lebih tinggi kelas bahayanya terhadap angin puting beliung.

\section{Karakteristik Kejadian}

Waktu kejadian angin puting beliung pada tahun 2008 yang melanda daerahnya terjadi pada waktu sore hari menjelang maghrib. Pada waktu ini sebagian penduduk tengah berada disekitar rumah setelah beraktivitas di tanah garapannya. Berdasarkan keterangan warga, sesaat setelah angin melanda kemudian aliran listrik padam. Berdasarkan pengamatan warga menyatakan bahwa angin kencang yang melanda pada waktu itu disertai putaran.

Citra tutupan awan selama satu hari yang telah direkam menunjukkan bahwa terjadi penggumpalan awan menjadi Cumulusnimbus $(\mathrm{Cb})$ di wilayah pesisir selatan Jawa dan bergerak dari arah barat daya menuju ke arah timur laut. Pada citra MTSAT Kanal IR1 tanggal 10 Februari 2008 ini, terlihat adanya perbedaan bentuk awan yang terekam pada pagi hari dan sore hari. Faktor cuaca ini mengakibatkan daerah yang tertutupi awan $\mathrm{Cb}$ mengalami hujan, sedangkan angin puting beliung yang melanda disebabkan oleh faktor rendahnya tekanan udara disekitar wilayah yang dilalui oleh angin. Rendahnya tekanan udara dipicu oleh penaikan temperatur udara di wilayah ini.
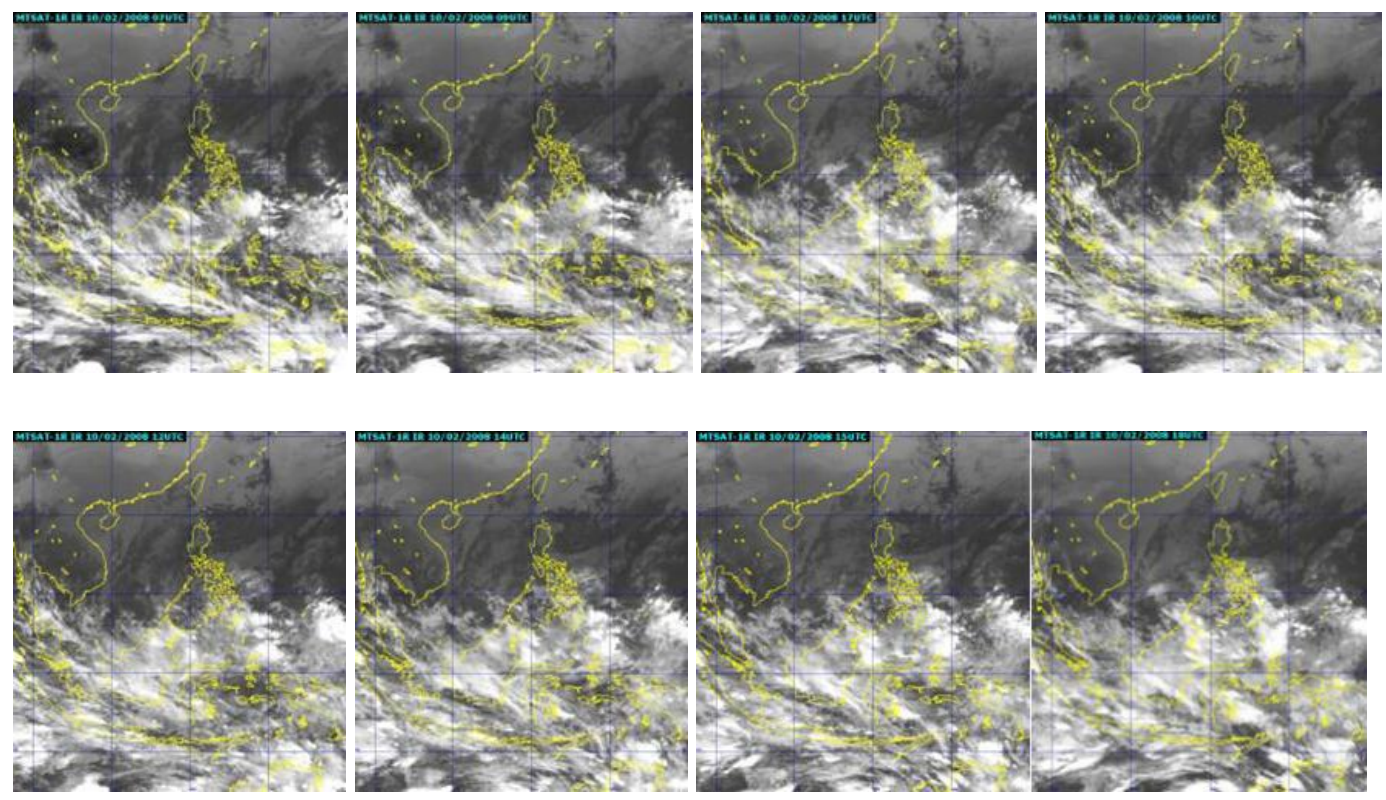

Gambar 3. Tampilan Awan Tanggal 10 Februari 2008 oleh Citra MTSAT Kanal IR1 Wilayah 
Indonesia (Sumber: dokumentasi Subbid Pengelolaan Citra Satelit BMKG Pusat, 2008)

\section{Penyusunan Database Bencana dalam Bentuk WebGIS}

Database ini dijadikan sistem informasi yang dinamai SIMADA_PB (Sistem Informasi Manajemen Dampak Puting Beliung). Untuk melakukan penyusunan web sistem informasi geografis untuk manajemen dampak bencana khususnya angin puting beliung, peneliti menggunakan perangkat lunak desain web Adobe Dreamweaver CS4, bahasa pemrograman PHP, javascript program googlemap api v3, dan sistem manajemen basis data MySQL.

\section{Pembuatan desain}

Pembuatan desain tampilan web dilakukan dengan bantuan perangkat lunak Adobe Dreamweaver CS4 menggunakan bahasa pemrograman PHP. Script pada tiap-tiap halaman web dibuat secara terpisah dengan tampilan utamanya diberi nama index.php. Tampilan web utama secara umum meliputi header yang berisikan file gambar header dengan ekstensi jpg. Dibagian bawah header disisipkan menu login dan logout khusus bagi administrator web ini untuk melakukan perbaruan data. Pada bagian kanan dan kiri terdapat tampilan menu halaman yang terdiri dari halaman beranda, halaman peta lokasi, halaman perbarui data, halaman survei kapasitas, halaman info, halaman link terkait, dan halaman hubungi kami. Khusus untuk halaman perbarui data tidak akan dapat diakses apabila tidak melakukan login terlebih dahulu. Jadi, halaman perbarui data hanyalah dapat diakses oleh administrator untuk menambah data baru maupun mengedit data lama. Adapun interkoneksi antar halaman web dapat dilihat pada gambar 4 berikut ini. 


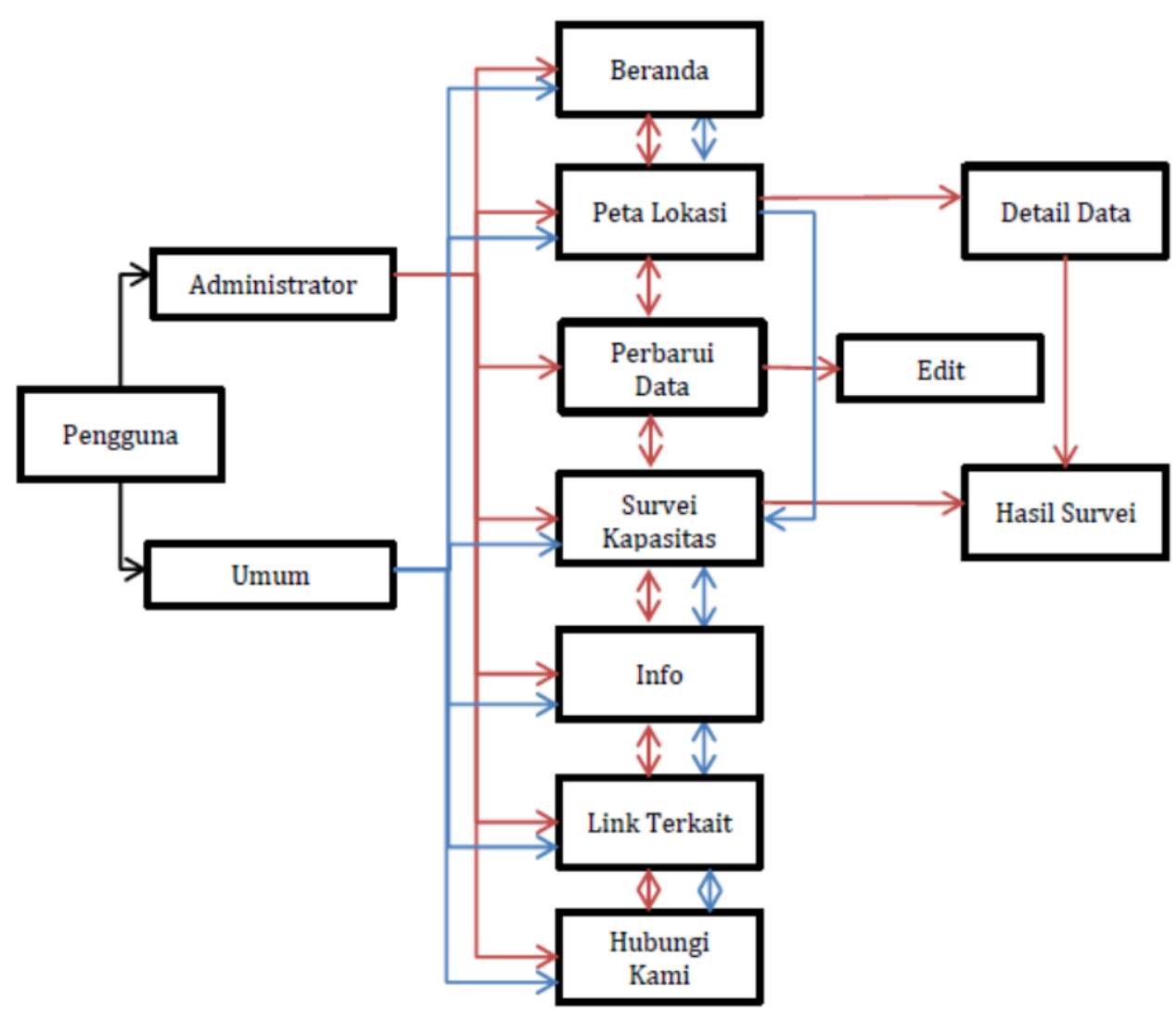

Gambar 4. Skema Antar Halaman Web SIMADA_PB

\section{Instalasi basis data}

Agar data dapat tersimpan ke dalam server, sebelumnya perlu dilakukan instalasi basis data terlebih dahulu. Basis data yang dipakai ialah MySQL yang berasal dari open source sofware bernama Xampp versi 1.7.2.

\section{Eksekusi tampilan}

Web Sistem Informasi Manajemen Dampak Bencana Puting Beliung ini masih menggunakan localhosting sehingga belum dipublikasikan secara luas tentang keberadaannya. Sementara ini penyusunan web hasil penelitian tentang bencana angin puting beliung di pesisir selatan Purworejo berusaha menampilkan objek terkena dampak yang berupa titik (point), arah angin yang berupa garis (line), dan daerah terlanda yang berupa luasan (polygon). Data tentang hasil penelitian ini merupakan data awal, selanjutnya dapat dilakukan perbaruan data oleh administrator dengan cara menambahkan data kejadian angin pada waktu yang berbeda. Disamping itu, web ini juga dapat digunakan sebagai alat untuk melakukan survei kapasitas masyarakat terhadap bahaya angin puting beliung seperti yang akan dibahas pada menu survei kapasitas. Desain tampilan yang telah dibuat seperti berikut ini. 


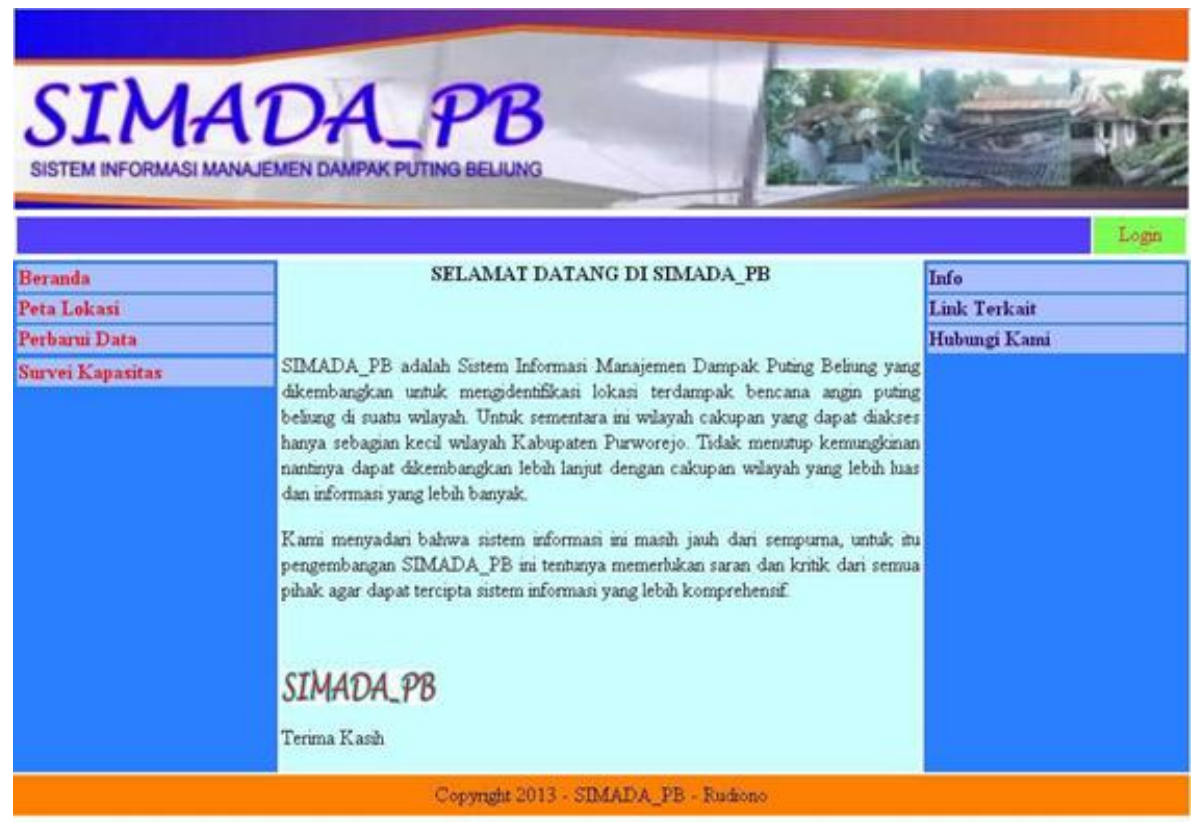

Gambar 5. Tampilan SIMADA_PB

Menu yang ditampilkan dalam web ini ditampilkan pada sisi kanan dan kiri halaman utama sebagai berikut:

1. Menu Login

Menu login dikhususkan untuk user yang memiliki akun dan password untuk penambahan data baru. Menu login ini akan dikelola oleh admin yang diberi kewenangan dalam pengelolaan sistem informasi ini. Untuk login dan mengelola web ini diperlukan nama pengguna dan password yang telah terdaftar sebelumnya. Dari menu ini pengguna yang diberi hak untuk mengelola dapat mengisikan data kedalam halaman perbarui data.

2. Menu Beranda

Menu beranda merupakan menu utama tampilan web. Menu ini difungsikan sebagai index saat pertama kali mengakses web ini. Setiap pengguna bebas mengakses halaman ini.

3. Menu Peta Lokasi

Peta lokasi yang ditampilkan kedalam web ini menggunakan aplikasi umum yang beredar di internet yaitu Googlemap Api v3. Dalam web ini, peta dapat diakses oleh semua pengguna yang sedang mengakses tanpa harus login seperti halnya pengelola. Layer yang tersedia di menu peta ini adalah layer objek terkena dampak, layer daerah terlanda dan layer arah angin. 


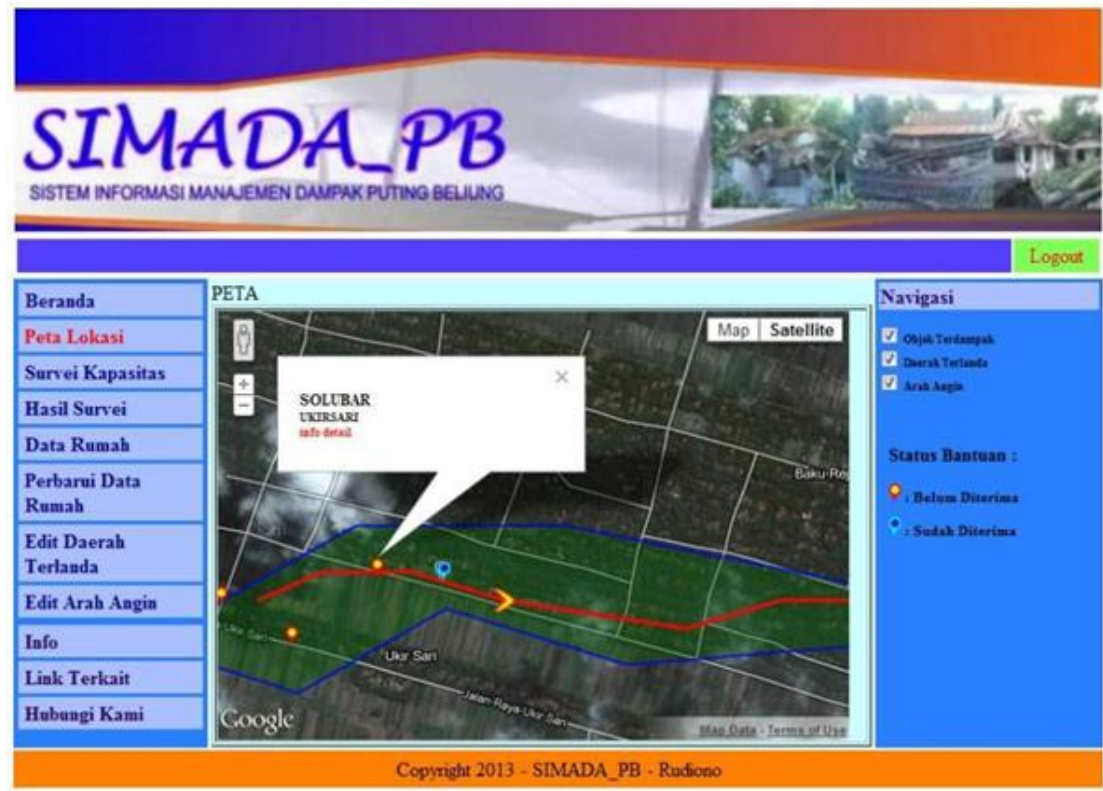

Gambar 6. Layer Peta yang Berada di Menu Peta Lokasi

4. Menu Perbarui Data

Khusus untuk menu ini, akses halaman tidak untuk semua pengguna. Menu ini dikhususkan bagi admin atau pengelola web untuk melakukan perbaruan data. Data yang dapat diunggah kedalam web yaitu:

a. Tanggal kejadian angina (teks)

b. Nama pemilik/nama korban (teks)

c. Foto pasca bencana (file jpg, bmp, png)

d. Kualitas bangunan (opsi: permanen dan non permanen)

e. Alamat lengkap (teks)

f. Kode pos (numerik)

g. Latitude (posisi geometrik)

h. Longitude (posisi geometrik)

i. Nomor telepon/hp korban (numerik)

j. Jumlah kerugian materi

k. Status bantuan (opsi: sudah diterima dan belum diterima)

I. Deskripsi tentang kondisi korban (teks maksimal 240 karakter)

m. Foto tambahan

5. Menu Survey Kapasitas

Menu survei kapasitas juga dapat diakses oleh semua pengguna yang membuka situs ini. Maksud dari penayangan menu survei ini agar dapat digunakan oleh pengguna sebagai media untuk mengukur kapasitas masyarakat. Masyarakat umum sebagai pengguna dapat menuliskan nama dan alamat lengkap sesuai identitas agar nantinya data yang terekam dalam basis data merupakan data asli tanpa rekayasa.

\section{Tanggapan Pemangku Kebijakan Lokal di Kabupaten Purworejo Mengenai Penyusunan SIMADA_PB}


Sistem informasi yang telah disusun kemudian diujikan pengoperasiannya pada pihak yang berkepentingan yaitu Badan Penanggulangan Bencana Daerah (BPBD) Kabupaten Purworejo dan Badan Perencanaan dan Pembangunan Daerah (BAPPEDA) Kabupaten Purworejo. Pengujian ini dimaksudkan untuk melihat tanggapan pemangku kebijakan terkait keberadaan sistem informasi ini. Selain itu, masukan dan saran dari instansi tersebut dapat dijadikan acuan dalam pengembangan sistem informasi ini agar menu-menu layanannya lebih lengkap.

BPBD Kabupaten Purworejo menyambut baik hadirnya SIMADA_PB yang telah disusun. Setelah diujikan pengoperasiannya di kantor BPBD Kabupaten Purworejo, SIMADA_PB pada intinya layak untuk dijadikan alat yang dapat dipakai untuk pengumpulan data kebencanaan. Dari segi tampilan dan pemilihan warna dalam SIMADA_PB ini sudah baik atau menarik. Menu-menu yang disajikan dalam SIMADA_PB sangat mudah untuk dipahami ketika akan mengoperasikannya.

Tanggapan atas hadirnya SIMADA_PB dari pihak BAPPEDA Kabupaten Purworejo sangat baik. Informasi yang ditampilkan masih perlu ditambah seperti berita terkini dengan teks berjalan yang dapat dilihat atau dibaca ketika pengguna mengakses SIMADA_PB. Dengan menu yang ada saat ini SIMADA_PB sudah layak dipakai untuk menginventarisasi objek terkena dampak angin puting beliung. Survei kapasitas yang ditampilkan dalam SIMADA_PB dianggap sangat penting dijadikan alat untuk mengukur kapasitas masyarakat menghadapi bencana angin puting beliung.

\section{SIMPULAN}

Sebaran daerah terlanda berada di empat desa yaitu Desa Ukirsari, Desa Pasaranom, Desa Bakurejo dan Desa Sumberagung. Jumlah rumah yang rusak akibat bencana ini sebanyak 87 unit dan 1 unit tempat ibadah. Sebaran rumah yang rusak tidak merata, dengan populasi terbanyak rusak yaitu di Desa Ukirsari. Keberadaan pohon rapuh disekitar rumah menjadi salah satu penyebab kerusakan bangunan.

Analisis kelas bahaya terhadap empat desa ini dilakukan dengan pemberian bobot terhadap kepadatan jumlah objek terkena dampak. Hasil pembobotan menghasilkan peta kelas bahaya dengan tiga tingkat yaitu kelas bahaya rendah, kelas bahaya sedang, dan kelas bahaya tinggi. Kejadian bencana angin ini berdampak pada daerah dengan luas $0,95 \mathrm{~km}^{2}$. Sedangkan panjangnya lintasan angin puting beliung yang melanda sepanjang 4,30 km kearah timur laut. Terjadi pelemahan kecepatan angin yang berasal dari arah barat daya menuju timur laut.

Penyusunan database berbentuk web GIS ini menggunakan bahasa pemrograman PHP dan basis data MySQL yang masih berada pada localhosting. Peta yang disisipkan dalam web ini merupakan opensource map yang diperoleh dari googlemap api v3. Hasil yang telah disusun adalah peta sebaran daerah terlanda disertai layer rumah terkena dampak (point), layer daerah terlanda (polygon), dan layer arah angin (line). Selain itu juga terdapat menu khusus admin untuk menambah dan mengedit data. Menu tambahan berupa analisis survei kapasitas masyarakat yang hasil pengharkatannya dapat dilihat setelah form survei terisi.

\section{DAFTAR PUSTAKA}


GLG Jawa Tengah, 2008, Pedoman Penyusunan Rencana Aksi Daerah (RAD) Pengurangan Risiko Bencana (PRB) bagi Kabupaten/Kota. Semarang: Good Local Governance (GLG) Jawa Tengah

Kedaulatan Rakyat, 2012, Pesisir Selatan Purworejo Rawan Angin Kencang, SKH Kedaulatan Rakyat Edisi 24 Maret 2012, http://krjogja.com/read/122868/pesisirselatan-purworejo-rawan-angin-kencang.kr (diakses 3 Mei 2012).

Suara Merdeka, 2008, 84 Rumah Porak Poranda Diterjang Lisus, Harian Suara Merdeka Edisi 12 Februari 2008, http://www.suaramerde ka.com/v1/index.php/read/cetak/2008/02/12/645/84-Rumah-Porak-Poranda-Di terjang- Lisus (diakses 28 April 2012).

Suara Merdeka, 2012, Angin Lisus Terjang Pesisir Pantai Selatan, Harian Suara Merdeka Edisi 20 Maret 2012

UN/ISDR, 2013, Terminology on DRR, http://www.unisdr.org/we/inform/terminology \#letter-h diakses tanggal 5 April 2013 